\title{
Análisis comparativo de las políticas culturales a nivel local
}

\author{
Enrique Espinoza Pinales \\ eppinales@gmail.com \\ Museo de los Yaquis, Cócorit, Sonora
}

\begin{abstract}
Resumen. El propósito principal del presente ensayo es aportar elementos conceptuales e históricos para una reflexión crítica sobre los procesos de gestación y desarrollo de las políticas culturales en el plano local, y como estos son producto de procesos de construcción a nivel internacional y nacional y que pueda ser útil para los actores involucrados en la gestión y conducción de instancias culturales de la región.
\end{abstract}

Palabras clave: Estado, Diversidad cultural, Identidad cultural, Instituciones culturales, Gestión y Políticas culturales.

\section{Introducción}

Este trabajo es producto de una investigación documental en la que se consultaron diversas fuentes, que van desde páginas oficiales de Internet de varias instituciones culturales nacionales e internacionales, documentos oficiales de las instituciones estudiadas y archivos personales. Para tal propósito se hace una revisión de los procesos que han generado la aparición de los organismos locales encargados de dirigir los programas y políticas culturales y un análisis comparativo de dos modelos institucionales, sus planteamientos conceptuales y las líneas de trabajo que se implementan con el fin de contrastar dichos modelos.

\section{EI papel de la UNESCO en la formu- lación de las políticas culturales a nivel internacional}

El papel de la Organización de las Naciones Unidas para la Educación, la Ciencia y la Cultura (UNESCO) ha sido el de formular orientaciones generales que permitan a los estados miembros enmarcar y darle un rumbo a sus políticas públicas en el área de cultura. Pasos importantes en esta dirección es la declaración de la UNESCO (1966) en la que establece entre los principios de cooperación cultural internacional el reconocimiento de que cada cultura es un valor a respetar y preservar y que cada pueblo tiene el derecho a desarrollar su propia cultura, considerando que la diversidad cultural es parte del patrimonio de la humanidad.

La UNESCO ha sido una especie de caja de resonancia de la realidad internacional en materia de cultura, no sólo se ha hecho eco de las reflexiones e investigaciones de académicos e intelectuales sobresalientes, sino además ha recogido los clamores y las tendencias que se manifiestan en las dinámicas culturales de los diferentes países. De la Conferencia de Venecia a las Conferencias de África y de América Latina en los años 70 hasta llegar a la Conferencia Mundial sobre Políticas Culturales de México en 1982 las discusiones se han ido profundizando y se 
han ido incluyendo elementos claves para la definición de las políticas culturales en todo el mundo.

Parte de este proceso ha sido considerar a la cultura como un derecho humano y dejar atrás la vieja idea que reduce la cultura y a las artes para consumo de las elites, ampliando su comprensión a sus múltiples formas de la vida social como resultado de la diversidad humana. En la época del desarrollismo la UNESCO llamó la atención sobre la necesidad de considerar el desarrollo como un proceso integral en donde el ser humano tiene que ser el medio y el fin, poniendo énfasis en la dimensión cultural del desarrollo.

La polémica entre las ideas de "democratización de la cultura" y "democracia cultural" también ha arrojado luces a las definiciones de las políticas culturales, hoy en día pocas son las instituciones que hablan de la cultura como un producto que hay que repartir con justicia entre todos los sectores de la sociedad, contrariamente ahora se habla de la cultura como procesos en los que es muy importante el fomento de la capacidad creativa de la población y su participación tanto en los procesos de creación de bienes culturales como en la toma de decisiones de la vida cultural, su difusión y disfrute. Lo mismo ha pasado con la noción de identidad cultural el cual se ha incorporado a los discursos de las políticas culturales contemporáneas como un ingrediente necesario, con una fuerte carga de polémica y muy poco explícito (UNESCO, 2006).

\section{La noción de cultura e identidad cul- tural en la definición de políticas cul- turales}

Desde la UNESCO se ha formulado una visión sociológica del concepto de cultura, que proporciona los rasgos esenciales del cual se puede partir, sin embargo esto no es suficiente porque es sólo una parte del proceso, la otra parte que es absolutamente imprescindible es la construcción de consensos nacionales y regionales sobre el significado de las políticas culturales y su implementación por los diferentes actores sociales de cada país, las políticas culturales de un país no se pueden elaborar partiendo solamente de orientaciones generales, tienen que ser el resultado tanto de la visión de los actores sociales como de las necesidades y expectativas que se generan a partir de realidades específicas.

El problema de la identidad es parte de este proceso, porque es la imagen que los propios actores han construido sobre sí mismos y es fuente de sentido de todos los actos de la existencia, tanto en el plano individual como en el colectivo, lo problemático de esta noción es que puede provocar conflicto si se entiende como diferenciación excluyente en relación con

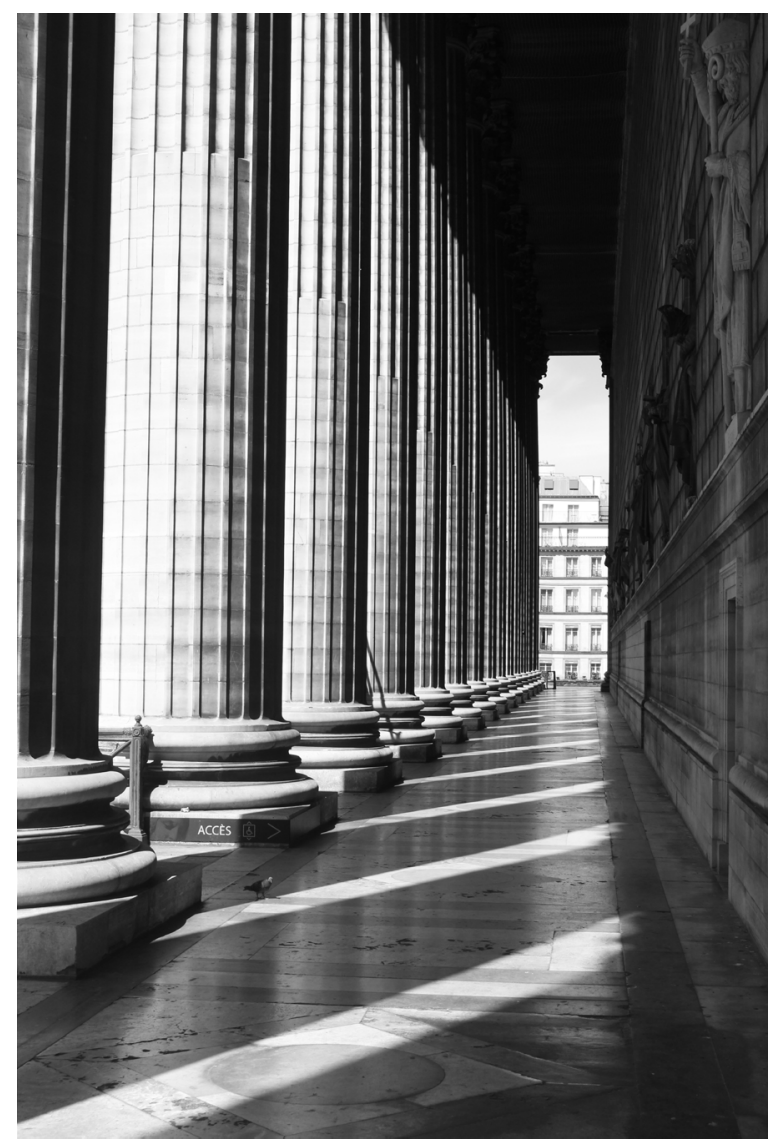

La Madelaine Fernando Serrano 
otras identidades. De hecho, muchos conflictos que existen a nivel mundial se ven agravados por las diferencias de carácter cultural. La noción de identidad cultural es quizás uno de los más contaminados por las ideologías nacionalistas que alimentan falsos orgullos a partir de una historia mitificada. Este concepto, el cual en los foros internacionales sólo se ha tocado superficialmente tiene que seguir estando en el centro de la discusión bajo una óptica critica que permitan desactivar muchos de los conflictos que ha generado en el mundo entero (Molano, 2007).

El problema de la identidad es que tiene un carácter muy complejo en donde intervienen no sólo ideas sobre la imagen de uno mismo y de los grupos a los cuales se pertenece, implica además una serie de valores y actitudes que se interiorizan a lo largo de la vida y pueden derivar en conflicto al entrar en contacto con otros grupos humanos por el simple hecho de entender la diferencia como un elemento que enfrenta a los grupos humanos.

\section{Políticas culturales en Latinoaméri- ca: entre la tradición y la modernidad}

La modernidad en América Latina existe como proyecto político de las elites gobernantes frustrado en muchos sentidos por la complejidad de las realidades locales, por un lado, por la persistencia de las tradiciones ancestrales en el mundo indígena y rural y sumando a ello las muchas deformaciones de los sistemas políticos nacionales con una fuerte tradición autoritaria que se resisten a adoptar los valores de la democracia occidental.

En ese sentido tienen razón tanto Roger Bartra como Octavio Paz, cuando el primero afirma que nuestra modernización es débil y fallida en muchos aspectos y en nuestros países se ha abusado del discurso de la modernidad provocando cierto hartazgo, y el segundo dice que "los latinoamericanos somos los comensales no invitados que se han colado por la puerta trasera de Occidente, los intrusos que han llegado a la función de la modernidad cuando las luces están a punto de apagarse". Ciertamente, América Latina no entró a la modernidad por la puerta delantera como invitado especial, aunque los grupos gobernantes hayan incorporado a su discursos los valores de la modernidad como un ideal a construir desde prácticas políticas obstinadamente pre modernas (Paz, 1970).

Hasta las dictaduras latinoamericanas hicieron suyo el discurso de la modernidad durante las décadas de los 70, 80 y 90 , con mayor razón países en los que la democracia es una gran simulación.

Para García Canclini (2003), no tiene sentido preguntarse si somos o no somos modernos, "la modernidad sólo es una característica que nos diferencia de otros procesos", "el problema fundamental es el de encontrar vías para construir otra globalización, basada en relaciones solidarias y en instrumentos para expresar la pluralidad de culturas y de caminos creativos".

Como proceso, la modernidad se ha ido instalando en todos los rincones de Latinoamérica a pesar de las resistencias y las contradicciones propias de la región. El problema no está en saber si se llegará a ser modernos o no, está claro que la modernidad nunca va a ser igual que la de los Estados Unidos o Europa, a la modernidad que me refiero tiene un carácter muy específico, frustrada, distorsionada, como realidad fantasmagórica o como se quiera, pero es una manera distinta de asumir la modernidad. Se concuerda que la manera más adecuada para entender la modernidad de Latinoamérica es su carácter contradictorio, y agregaría que estas tienen un carácter muy específico dado sus procesos históricos y sociales que nos han ido configurando como una región cultural con rasgos comunes. El reto central 
de América Latina es como insertarse en los procesos de globalización comercial y como estos procesos impactan a las expresiones culturales. Parte del reto es analizar los riesgos y las oportunidades en el patrimonio cultural y de las expresiones artísticas de cada región en el marco de los procesos de globalización. En síntesis, Latinoamérica necesita encontrar sus propias rutas de desarrollo en medio de todos los cruces de la globalización.

García Canclini (2003) ve a América Latina como un espacio compartido, que plantea la necesidad de pensar en diversas estrategias en la definición de políticas culturales que protejan nuestra diversidad cultural de manera urgente, sobre todo en ciertas áreas estratégicas.

En este contexto cobra gran relevancia los esfuerzos de la IX Conferencia Iberoamericana de Cultura realizada en Montevideo (OEI, 2006) que plantea una serie de fines:

- Afirmar el valor central de la cultura como base indispensable para el desarrollo integral del ser humano y para la superación de la pobreza y de la desigualdad.

- Promover y proteger la diferencia cultural que es el origen y fortalecimiento de la cultura iberoamericana, así como la multiplicidad de identidades lenguas y tradiciones que la forman y enriquecen.

- Consolidar el espacio cultural iberoamericano como un ámbito propio y singular, con base en la solidaridad, el respeto mutuo, la soberanía, el acceso plural al conocimiento y a la cultura, y el intercambio cultural.

- Facilitar los intercambios de bienes y servicios en el espacio cultural iberoamericano.

- Incentivar los lazos de unidad y de cooperación en el espacio cultual iberoamericano con otras regiones del mundo, así como alentar el dialogo intercultural entre todos los pueblos.

- Fomentar la protección y la difusión del patrimonio cultural y natural, material e inmaterial iberoamericano a través de la cooperación entre los países.

Creo que estos fines expresan una voluntad que pueden ser útiles para las diferentes naciones que conforman el espacio Iberoamericano, pero cada gobierno tiene que implementar mecanismos institucionales que le den viabilidad a dichos fines.

\section{Los procesos de configuración de las políticas culturales en Sonora}

En el estado de Sonora el debate sobre políticas culturales se ha dado de manera esporádica pero intensa, en momentos claves del proceso de conformación de las instituciones culturales de la entidad. Producto de las resonancias de la Conferencia Mundial sobre Políticas Culturales realizada en la ciudad de México en 1982 se crea el Consejo Nacional para la Cultura y las Artes (CONACULTA) en el año de 1988 como organismo rector de la política cultural del estado mexicano e inmediatamente después surgen sus contrapartes en las entidades de la republica (UNESCO, 2006).

El Instituto Sonorense de Cultura surge en 1989 como una réplica a escala del CONACULTA en donde los marcos normativos se establecen de manera casi mecánica, sin que mediara un proceso de diagnóstico y consulta a nivel estatal. Los primeros meses de existencia del ISC fueron para dotar al organismo de una estructura, acomodar todas las piezas sueltas (instituciones culturales como museos, bibliotecas, archivos, etc.) que habían funcionado dispersas en la estructura anterior y empezar a elaborar los programas culturales para la entidad (ISC, s/f).

La metodología para diseñar los prime- 
ros programas fue a través de una serie de actividades que fueron denominadas "Reuniones de análisis cultural en el estado de Sonora" entre junio y julio de 1989. En realidad, se trataba de reuniones de consulta realizadas en las cabeceras municipales más importantes del estado. Se establecieron cuatro ejes temáticos para enmarcar las ponencias y las discusiones, esto fueron: análisis de la promoción y la difusión de la cultura; conservación del patrimonio cultural; participación de la sociedad civil y ciencia y tecnología.

En estas reuniones participaron poco menos de 500 personas en once sedes, los cuales mostraron mayor preocupación por la conservación del patrimonio cultural que por proponer acciones orientadas a fomentar las expresiones artísticas y culturales. El formato de estas reuniones y la premura con la que se organizó dejó por fuera varios temas fundamentales y muchas de las inquietudes solo se tocaron de manera superficial. En muchos de los participantes quedo una sensación de haber participado en un simple acto protocolario, en donde no hubo tiempo para la reflexión y el análisis (Espinoza, s/f).

Académicos de la Universidad de Sonora y del Colegio de Sonora llamaron la atención sobre la falta de planeación de este proceso de consulta y la carencia de un encuadre metodológico para encausar las discusiones y propuestas. Fue una iniciativa limitada, que no fue capaz de propiciar la participación de la sociedad civil de manera amplia, finalmente las nuevas autoridades de cultura respondían más a las inercias del aparato burocrático que a la necesidad de crear un instrumento institucional que fortaleciera la vida cultural de la entidad.

En aquellos años el ISC formuló los primeros programas siguiendo los lineamientos del CONACULTA mostrando serias limitaciones para generar procesos de consulta y de vinculación con los actores locales para sentar las bases de un proyecto cultural propio. De entonces a la fecha han sido los festivales culturales y los concursos los que absorben la mayor parte de los recursos financieros y humanos de la institución, implementados con una visión centralista.

En aquel momento la polémica no salió del ámbito académico y de los pequeños círculos culturales de las ciudades más importantes del estado. Pasaron casi diez años para que se retomara la polémica con nuevos actores tanto del mundo académico como de los grupos de la sociedad civil. El ISC había cambiado poco en sus programas y estrategias para la difusión y promoción cultural, las inercias habían echado raíces, pero en este momento había más voces y mejor documentadas en la vida cultural de la entidad.

Entre 1997 y 1998 se realizaron por lo menos tres eventos importantes en los que el tema central eran las políticas culturales en el estado de Sonora, el primer evento fue convocado por las autoridades municipales de Cajeme (Ciudad Obregón) el cual fue denominado "Foro de planeación participativa La Cultura en Cajeme". Este evento se realizó durante tres días del mes de noviembre de 1997 en los que, a través de la discusión de un documento rector, un diagnóstico inicial y una serie de ponencias en varias mesas de trabajo se elaboraron las primeras propuestas para diseñar los planes y programas de la Dirección Municipal de Cultura. Según los documentos oficiales "el foro desde su planteamiento inicial fue concebido como un mecanismo de consulta ciudadana y el espacio propicio para generar una reflexión colectiva sobre la problemática cultural y sus perspectivas tanto a corto como a largo plazo" (Espinoza, s/f).

El segundo evento importante fue una reunión estatal de administradores de 
la cultura convocados por autoridades municipales de Hermosillo, a principios de 1998 con el propósito de hacer un balance del trabajo cultural de los municipios, intercambiar experiencias y formular propuestas de coordinación a nivel estatal. Y finalmente, como resultado de este nuevo ambiente caracterizado por un fuerte protagonismo de los Ayuntamientos en los programas de cultura de la entidad se organiza el Congreso Estatal de Cultura en abril de 1998 con la participación de organizaciones independientes de artistas y el apoyo de las autoridades municipales de Cajeme, Hermosillo y Ures en el Centro de las Artes de la Universidad de Sonora (Espinoza, s/f).

Una de las iniciativas de este congreso de cultura fue llevar una serie de propuestas al congreso estatal cuestionando una iniciativa de ley del gobierno del estado. En los pronunciamientos hechos en este congreso se señalaba la falta de voluntad del gobierno del estado para incorporar a la sociedad civil en los procesos de consulta y definición de las políticas culturales. En uno de los párrafos de uno de los documentos entregados al congreso se dice

Concebimos a la política cultural como resultado de un proceso que en primera instancia debe diagnosticar la problemática, las necesidades y las exigencias de la sociedad sonorense en materia de cultura, $y$ por otro lado implementar mecanismos de consulta con instituciones, organizaciones, grupos e individuos involucrados en el quehacer cultural y artístico que permita retomar los elementos que le den contenido y rumbo a los programas y planes de desarrollo cultural para el estado de Sonora.

Se buscaba romper con las inercias ins- titucionales y provocar la vinculación con la sociedad civil y por otro lado se buscaba establecer un marco normativo que permitiera una relación más justa entre el gobierno estatal y los gobiernos municipales con el propósito de enfrentar los grandes rezagos en materia de infraestructura cultural y la formulación de programas estratégicos en materia de formación y capacitación cultural. Se planteaba en el mismo documento la necesidad de establecer programas de vinculación entre el sector educativo y el cultural y lo mismo la necesidad de aprovechar espacios disponibles en los medios de comunicación para la difusión de la cultura.

La polémica que se vivió entre 1997 y 2000 en el estado de Sonora puso en evidencia los grandes vacíos que existen en materia de políticas culturales a nivel estatal y la emergencia de nuevos actores en el escenario de la vida cultural. Dichos vacíos en materia de políticas y programas culturales en el plano municipal han sido cubiertos tradicionalmente por la presencia de organizaciones de la sociedad civil y las instituciones de educación superior quienes asumen en muchos casos las responsabilidades de los gobiernos.

Muchos de los protagonistas de la polémica de los noventa eran artistas formados en el centro del país y establecidos recientemente en la entidad que participaban en organizaciones independientes de artistas, otros eran académicos de las universidades locales quienes de pronto se encontraron ante la oportunidad de influir en las políticas públicas. La composición plural de los gobiernos municipales de esa época le dio un dinamismo nunca antes visto a la vida cultural del estado y se retomaron muchas de las premisas generadas por los organismos internacionales, pero buscando su aplicación a las realidades locales. Fue una 
época en la que se cuestionó muy enfáticamente la concepción de cultura que la reduce a las expresiones artísticas para consumo de las elites y se intentó darle forma a un proyecto cultural en donde estuvieran presente las iniciativas de los diferentes sectores de la comunidad (Espinoza, $\mathrm{s} / \mathrm{f}$ ).

5. Análisis comparativo de políticas culturales de dos ciudades (Hermosillo, Capital de Sonora en México y Barcelona, capital del Cataluña en España)

\section{El Instituto Municipal de Cultura y Arte de Hermosillo}

Hermosillo, ciudad capital del estado de Sonora, con una población de 707,890 habitantes, es la ciudad más poblada de la entidad con cerca del $30 \%$ de la población total del estado.

El Instituto Municipal de Cultura y Arte (IMCA) fue creado en el 2004 como un órgano descentralizado de la Administración Pública Municipal, con personalidad jurídica y patrimonio propio. Los órganos que lo conforman son: Junta de Gobierno, un Consejo Consultivo, la Dirección General y un Comisario.

El IMCA administra nueve bibliotecas,

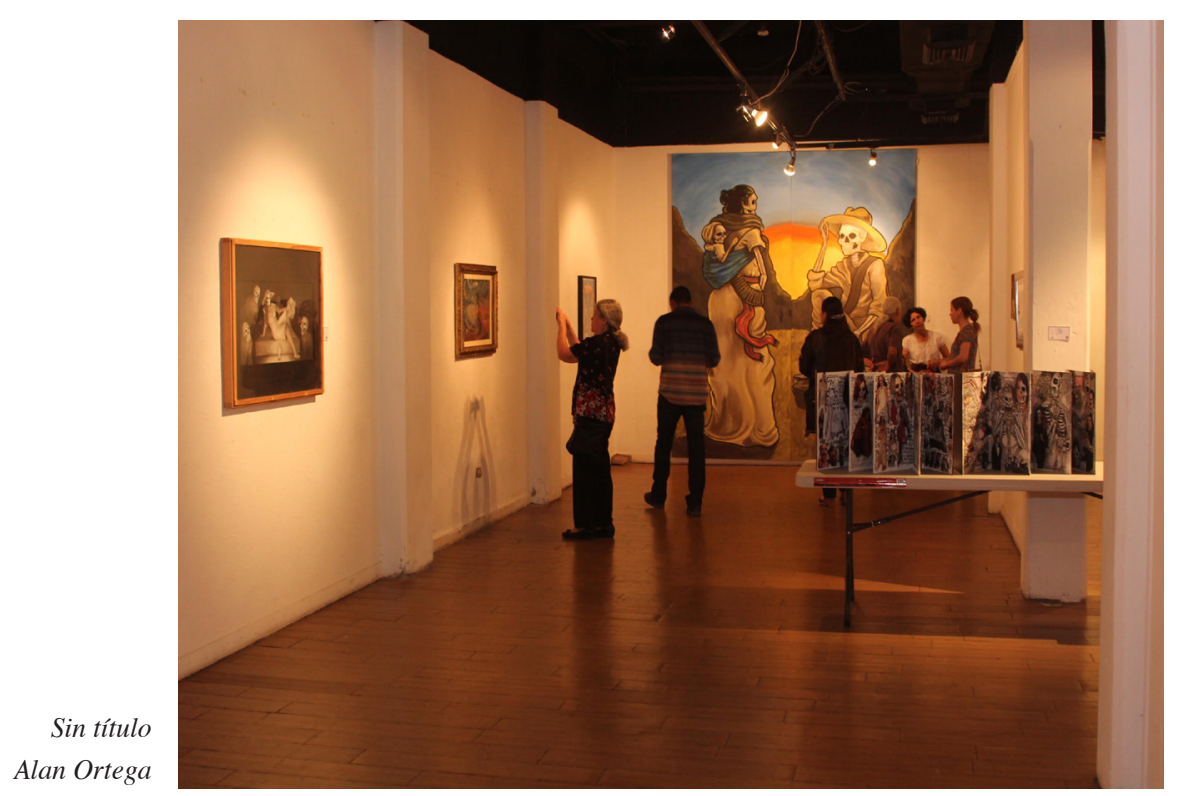

varias de las cuales funcionan como centros culturales en donde se ofrecen talleres artísticos. Opera el Programa de Desarrollo Cultural Municipal (fondo tripartita) que otorga apoyos económicos a artistas, promotores culturales y organizaciones mediante convocatoria abierta anualmente. Organiza un concurso nacional de poesía en honor a "Alonso Vidal" (Ayuntamiento de Hermosillo, 2017).

En la página oficial se declara que la política cultural se orienta hacía el desarrollo humano, material y espiritual, beneficiando a toda la comunidad, pero considerando como sectores prioritarios a los niños y jóvenes. Se plantea como orientaciones generales el promover el uso creativo del tiempo, el enriquecimiento del patrimonio cultural. Así como fomentar ámbitos de encuentro que favorezcan la cohesión social; contribuir al desarrollo turístico del municipio. La institución promueve la conservación del medio ambiente, la cultura de la paz y la tolerancia; la democracia como forma de vida; y preservar los usos, costumbres y tradiciones del municipio y los grupos étnicos que en él habitan (Ayuntamiento de Hermosillo, 2017). Entre sus objetivos destacan: fomentar en los ciudadanos una formación artística y cultural que favorezca la creación e innovación y garantice la continuidad de las tradiciones artesanales y artísticas autóctonas e involucrar a los artistas en el desarrollo cultural del municipio; posicionar a Hermosillo como un municipio educador y como una comunidad que privilegia el conocimiento; posicionar a Hermosillo como destino turístico a través de sus distintos recursos; fortalecer las identidades específicas de los barrios y colonias de Hermosillo (Ayuntamiento de Hermosi1lo, 2017).

Durante los últimos años se han desarrollado programas (Cultura sobre ruedas) enfocados a promover la lectura y el arte en espacios como asilos de ancianos, ca- 
sas hogar y CERESOS, además turismo cultural mediante recorridos por sitios históricos (trolebús turístico), así como actividades en espacios públicos tradicionales de la ciudad (andador cultural) en la que exponen y venden sus obras artistas, artesanos urbanos e indígenas y creadores de arte popular de Hermosillo en plazas públicas.

Destacan programas como la Orquesta Sinfónica Juvenil y el Coro Infantil Municipal que busca promover el canto y la música entre niños y jóvenes. Uno de los programas más sobresalientes son las Fiestas del Pitic, que durante varios años se ha llevado a cabo en el centro histórico de Hermosillo. Este es un festival cultural callejero en el que participan cada año miles de turistas y pobladores quienes durante cuatro días celebran el aniversario de la ciudad con una gran diversidad de eventos culturales (conciertos musicales, teatro, presentaciones de libros, conferencias, exposiciones de artes visuales, tianguis artesanal, etc.) (Ayuntamiento de Hermosillo, 2017).

Uno de los aciertos del IMCA es haber logrado un cierto grado de autonomía como entidad municipal y haber integrado a su estructura la representación de la sociedad civil como órganos de consulta y de planeación. La política cultural se enmarca en una política de desarrollo social que pone énfasis en la tarea educativa (municipio educador) y retoma líneas estratégicas que se promueven como políticas generales (Conservación del medio ambiente, cultura de la paz y la tolerancia, democracia, etc.).

Las políticas culturales del IMCA van más allá de la concepción que reduce la cultura a las llamadas Bellas Artes y retoma una serie de valores que tienen que ver con el desarrollo humano integral tanto en el plano individual como colectivo, como lo es la promoción de: la conservación del medio ambiente, la cultura de la paz y la tole- rancia; la democracia como forma de vida; y la preservación de los usos, costumbres y tradiciones del municipio y los grupos étnicos que en él habitan. Así como fomentar espacios de encuentro que favorezcan la cohesión social.

Aunque algunos de los planteamientos programáticos del IMCA coinciden con los principios de la Agenda 21, esta no se asume de manera explícita. En ningún documento oficial se plantea la cultura como un derecho social básico de los ciudadanos, y una vía de inclusión social para sectores que sufren discriminación, como son los grupos minoritarios de los que forman parte los migrantes. Tampoco se toca el problema de las nuevas identidades ante el fenómeno de la globalización y la presencia de una sociedad cada vez más plural y diversa.

El IMCA no ha llegado a ese nivel de compromiso en donde la cultura se asume como un derecho colectivo y como un poderoso instrumento que permite dar respuesta a muchos de los problemas que ha provocado la globalización.

También llama la atención que a nivel presupuestal la mayor parte de los recursos se destinan a la realización de festivales culturales como son las Fiestas del Pitic con el que se celebra el aniversario de la ciudad con una gran diversidad de eventos, en los que destacan los eventos masivos (conciertos musicales).

\section{Instituto de Cultura de Barcelona, España}

Barcelona es capital de Cataluña España en el noreste del país. Con una población de 1.6 millones de habitantes, Barcelona es la segunda ciudad española más poblada y la décima de la Unión Europea. El Área Metropolitana de Barcelona, integrada por 36 municipios, tiene una población de 3.2 millones.

Barcelona frecuentemente es escenario 
de diversos eventos mundiales. El Instituto de Cultura fue creado en 1996. Se organiza a partir de una Junta de Gobierno. En esta instancia superior están representados todos los grupos políticos que forman parte de la ciudad (profesionales de la cultura y representantes sindicales). Este organismo aprueba los planes de actuación anuales y hace un seguimiento de las actuaciones que lleva a cabo el Instituto. La institución se maneja con criterios gerenciales, quien está al frente es un director-gerente, al lado de un comité de Dirección (Barcelona Cultura, s/f).

El Instituto de Cultura se rige por un plan estratégico de la ciudad y se concreta en los siguientes objetivos: consolidar la cultura como estrategia básica de desarrollo de la ciudad del conocimiento; favorecer las actividades de cultura popular y tradicional, así como las actividades de las asociaciones culturales de Barcelona; completar y remodelar los equipamientos patrimoniales de la ciudad y mejorar su gestión; incentivar la dimensión educativa de la cultura; facilitar la incorporación de los sectores culturales a los flujos de la era digital; implementar el plan de bibliotecas; articular acciones para mejorar la actuación cultural en los barrios y distritos de la ciudad (Barcelona Cultura, s/f). En este plan se articula la visión de las políticas culturales como proyecto de ciudad, en alianza con los diferentes sectores de la sociedad, se pone especial atención a la participación del sector empresarial con el objetivo de situar la cultura de Barcelona como uno de los principales activos del desarrollo y de la proyección de la ciudad, a través de la gestión de los equipamientos y los servicios culturales municipales y promover y facilitar la emergencia y la consolidación de las múltiples plataformas y proyectos culturales de iniciativa privada en la ciudad (Barcelona Cultura, s/f).

Barcelona sitúa a la cultura en el centro de las políticas públicas de cara a los retos que imponen los cambios en la era de la globalización (tecnologías de la información, las migraciones y nueva composición social de las ciudades). Consideraciones básicas del plan estratégicos son: influencia de las industrias culturales y la necesidad de que las políticas culturales ejerzan un contrapeso a los efectos de banalización mediática.

Barcelona es uno de los mejores ejemplos de políticas culturales que se conciben como parte central de las políticas públicas buscando potenciar el papel protagónico de los diferentes sectores sociales y situarse a la altura de los retos de la era de la globalización y sus efectos en la conformación de las nuevas identidades, la digitalización de la cultura y los efectos perniciosos de las industrias culturales (empresas trasnacionales).

Un elemento destacable en varias dependencias es el esfuerzo de incorporar a representantes de la sociedad civil en la estructura, tanto en tareas de planeación, seguimiento y evaluación.

El Ayuntamiento de Barcelona es uno de los principales promotores de la Agenda 21, en la que se retoma la inclusión social y la democracia participativa como valores centrales de la organización mundial de Ciudades y Gobiernos Locales en la que se promueve el dialogo intercultural y se busca garantizar los derechos humanos fundamentales como uno de los ejes básicos de las políticas públicas.

Ejemplos de la clara orientación de los programas culturales en Barcelona es el compromiso del Ayuntamiento de hacer llegar los servicios culturales a toda la población a nivel individual, vecinal y comunitario, independientemente de su origen y creencias religiosas. Existe, como parte de los programas un área de atención a los inmigrantes, extranjeros y refugiados. Existen planes orientados a promover la integración social de perso- 
nas de diferentes orígenes culturales que fomentan la tolerancia y la solidaridad (espacios de conocimiento, fiestas colectivas, etc.) (Barcelona Cultura, s/f).

A través de las expresiones artísticas como las artes visuales también se promueve el valor de la diversidad cultural invitando a pintores, escultores y fotógrafos de diferentes regiones del mundo a mostrar sus visiones del mundo desde su propia perspectiva estética y cultural (África, Asia y América latina). Por ejemplo, en el programa de exposiciones organizadas por el Instituto de Cultura de Barcelona se presentan: La condición transmigrante, Globalización y ciudad, Chabolas, La ciudad informal, Áfricas, etc.

El Ayuntamiento promueve el programa Barcelona Diálogo Intercultural que se desarrolla durante el año 2008. Barcelona a través de su propuesta cultural le apuesta a la diversidad cultural como palanca de desarrollo social en el que la convergencia de culturas constituye la oportunidad para enriquecer la vida de la ciudad. Define su vocación como una ciudad abierta a todas las expresiones culturales en coexistencia creativa, fomentando el acercamiento, la interacción y el conocimiento mutuo, para potenciar y enriquecer el bagaje cultural colectivo. El proyecto de ciudad busca construir una sociedad cohesionada y plural capaz de convivir en la interculturalidad como su principal riqueza (Barcelona Cultura, s/f).

\section{Conclusiones}

- El papel que ha jugado la UNESCO en la definición de las políticas culturales en los distintos países de todo el mundo ha sido determinante, sin embargo, habría que verlo como un proceso de ida y vuelta, ya que las reflexiones que se generan en las instancias internacionales son producto de los que ocurre en los diferentes países, lo cual proporciona los elementos básicos para formular dichas orientaciones y plantearlas como alternativas. La UNESCO sólo tiene la facultad y la capacidad para formular recomendaciones, las cuales por su misma naturaleza sólo pueden ser de carácter general, aplicables a cualquier país o región dependiendo del interés y la decisión de los gobiernos.

- Herederos de los debates en materia de políticas culturales de la UNESCO a partir del IV Foro de Autoridades Locales de Porto Alegre, reunido en Barcelona en mayo de 2004 la iniciativa la toman los gobiernos locales quienes en el documento Agenda 21 de la Cultura establecen las bases de una nueva visión de las políticas culturales.

- Los gobiernos locales, como son los casos de Hermosillo y particularmente el caso de Barcelona ponen en evidencia que no son suficientes las orientaciones generales de la UNESCO para definir las políticas culturales, de la misma manera no se pueden aplicar mecánicamente los lineamientos federales a los estados, y de los estados a los municipios. El proceso de construir políticas culturales en los distintos niveles tiene que ver con dinámicas muy específicas en las que se articulan las visiones de lo cultural con intereses, necesidades y expectativas de los actores sociales. El eslabón más débil es el ámbito municipal en donde se aplican los programas con seres humanos reales, es ahí donde la gente percibe la existencia o inexistencia del estado a través de sus políticas públicas, es ahí donde se tienen que rediseñar las políticas culturales a partir de las nuevas realidades, en donde ya no se puede hablar de identidad, sino de identidades en movimiento lo cual obliga a las instituciones culturales a reinventarse constantemente, con políticas que tomen en cuenta la complejidad y el dinamismo de la vida moderna o posmoderna. 
- En el diseño y elaboración de las políticas culturales se tienen que abrir espacios de reflexión y discusión sobre el problema de la identidad cultural no sólo en el plano nacional, sino en las regiones y en los municipios para cambiar la idea de la identidad como exclusión y conflicto, además la necesidad de fomentar valores de respeto en un mundo en el que la tendencia es reunir en los mismos espacios una gran diversidad de culturas. Esto sólo es posible a través de amplios programas tanto de educación formal como informal, tiene que ser parte de los contenidos educativos de la institución escolar y de los medios de comunicación, lo mismo los centros culturales deben considerarlo como uno de los ejes de sus políticas.

- Las políticas culturales tienen que ser el resultado de las múltiples historias que hay en una sociedad, en concordancia con las tendencias del mundo contemporáneo, esto significa que en su definición tiene que estar el pasado y el presente, y las expectativas de futuro de la población. Los ejes de cualquier política cultural, tanto a nivel nacional como local tienen que ser la de promover el respeto a la pluralidad étnica y social y crear condiciones que favorezcan el acceso a los bienes y servicios culturales de todos los sectores de la población, así como poner mayor énfasis en los procesos que permiten crear los bienes culturales y como estos circulan en la sociedad, generando sus propios significados en la vida de los individuos que en los llamados productos culturales generalmente asociados exclusivamente con la actividad artística. Esto significa que las políticas culturales tienen que ir más allá del apoyo a la actividad creadora de los artistas, la cual sigue siendo limitada e insuficiente, sobre todo en los municipios.

- Las políticas culturales tienen que ser parte integral de las políticas de desarrollo social que permitan construir puentes para un dialogo creativo entre los distintos sectores de una comunidad en un marco de equidad socioeconómica, generacional y de género.

\section{Bibliografía}

Ayuntamiento de Hermosillo. (2017). Cultura y Arte. Directorio Artístico IMCA Hermosillo. Recuperado de: http://www.imcahermosillo.com.mx/cultura-y-arte/

Barcelona Cultura. (s/f). Instituto de Cultura. Recuperado de: http://lameva.barcelona. cat/barcelonacultura/es/icub

Bartra R. (2005). La jaula de la Melancolía. Identidad y metamorfosis del mexicano. Editorial Grijalbo: México.

Espinoza E. (s/f). Archivos personales.

García N. (2003). Culturas hibridas. Estrategias para entrar y salir de la modernidad. Paidós: México. Recuperado de: https://cbd0282.files.wordpress.com/2013/02/ culturashibridas.pdf

ISC. (s/f). ¿Quiénes somos? Antecedentes. Recuperado de: http://isc.gob.mx/quienes-somos/antecedentes/

Naciones Unidas. (s/f). Declaración universal sobre la diversidad cultural. Adoptada por la 31a reunión de la Conferencia General de la UNESCO, París, 2 de noviembre de 2001. Recuperado de: http://www.ohchr.org/SP/ProfessionalInterest/ Pages/CulturalDiversity.aspx 
Molano, O. (2007). Identidad cultural un concepto que evoluciona. Revista Opera, No.

7, 69-84. Recuperado de: http://www.redalyc.org/articulo.oa?id=67500705>

ISSN 1657-8651

OEI. (2006). Carta Cultural Iberoamericana. IX Conferencia Iberoamericana de

Cultura Montevideo. Ministerio de Educación y Cultura. República Oriental de

Uruguay. Recuperado de: file:///C:/Users/csalguero/Downloads/cCultural.pdf

Paz, O. (1970). Posdata. Editorial Siglo XXI: México.

UNESCO. (2006). Cultura. Declaración de México sobre las Políticas Culturales.

Conferencia Mundial sobre las Políticas Culturales, México D.F., 6 de agos-

to de 1982. Recuperado de: http://portal.unesco.org/culture/es/ev.php-URL_

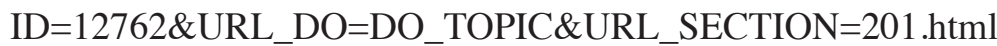

UNESCO. (s/f). Plan de Acción sobre Políticas para el Desarrollo. Adoptada en la Conferencia Cultural Intergubernamental sobre Políticas Culturales para el Desarrollo, Estocolmo, 2 de abril de 1998. Recuperado de: http://unesdoc.unesco.org/ images/0011/001163/116393So.pdf

UNESCO. (1966). Instrumentos Normativos. Declaración de los Principios de la

Cooperación Cultural Internacional. Recuperado de: http://portal.unesco.org/es/ ev.php-URL_ID=13147\&URL_DO=DO_TOPIC\&URL_SECTION=201.html

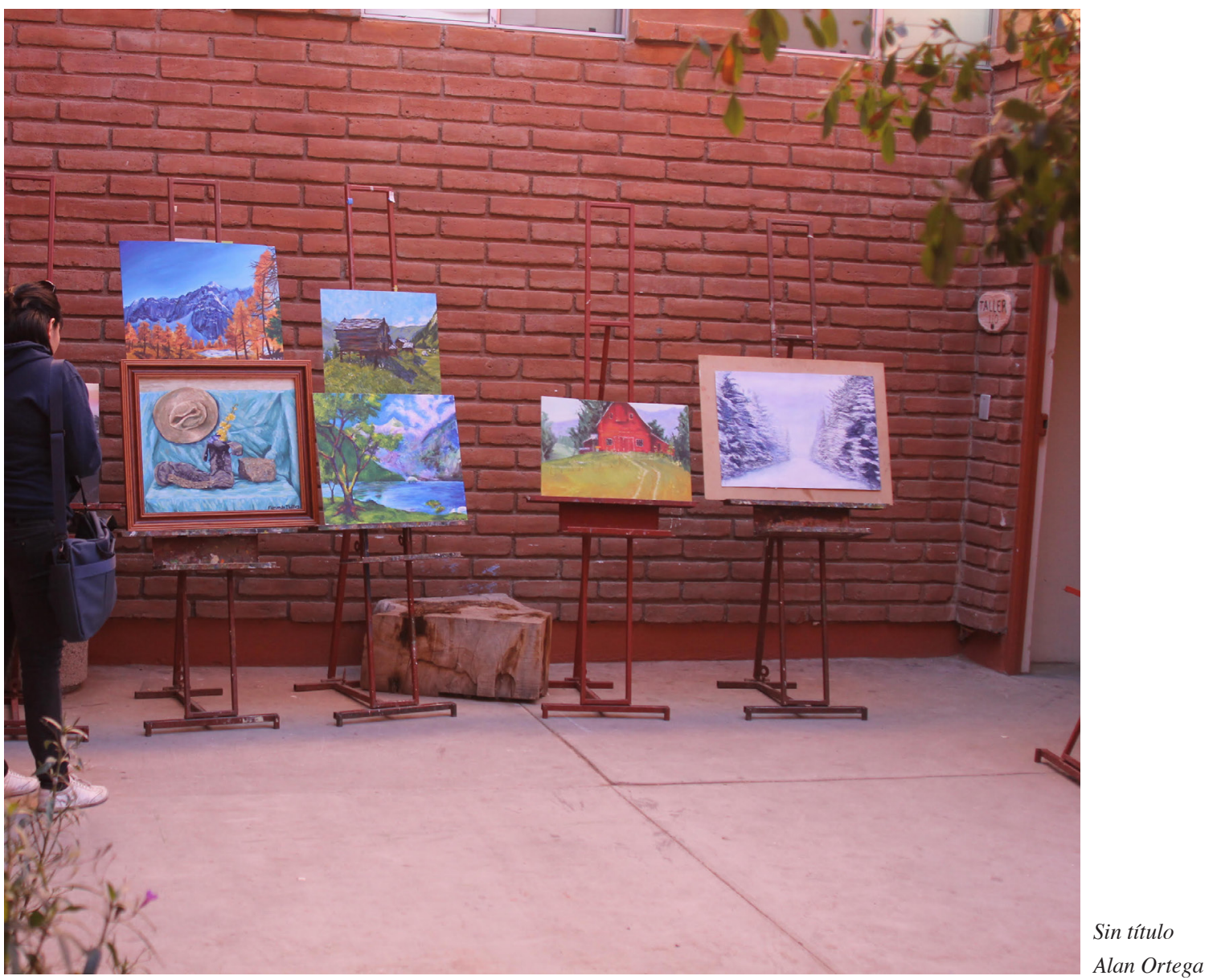

